\title{
Musical Sounds, Motor Resonance, and Detectable Agency
}

\author{
JACQUES LAUNAY \\ Department of Experimental Psychology, University of Oxford
}

\begin{abstract}
This paper discusses the paradox that while human music making evolved and spread in an environment where it could only occur in groups, it is now often apparently an enjoyable asocial phenomenon. Here I argue that music is, by definition, sound that we believe has been in some way organized by a human agent, meaning that listening to any musical sounds can be a social experience. There are a number of distinct mechanisms by which we might associate musical sound with agency. While some of these mechanisms involve learning motor associations with that sound, it is also possible to have a more direct relationship from musical sound to agency, and the relative importance of these potentially independent mechanisms should be further explored. Overall, I conclude that the apparent paradox of solipsistic musical engagement is in fact unproblematic, because the way that we perceive and experience musical sounds is inherently social.
\end{abstract}

Submitted 2014 April 23; accepted 2014 June 28.

KEYWORDS: music, social, motor, empathy, agency, sound

MUSIC exists in all human cultures around the world (Blacking, 1973), and is argued to have evolved as an important technology for social communication (Huron, 2001). Given its prevalence and importance it is likely that the ability to make music conferred some adaptive advantage for groups of humans who developed this technology (although see Pinker, 1997, for an alternative view). There are a number of explanations put forward for this, including sexual selection, group level social bonding, perceptual and motor rehearsal, and mother-child bonding (for some discussion of these see Cross \& Morley, 2009; Hagen \& Bryant, 2003; Huron, 2001). It is likely that all of these benefits of music were influential during its development and spread amongst humans, but here I am interested in the theory that musical engagement could be beneficial in creating and indicating social bonds within groups of people. If this were one of the key factors driving the development of music, we would expect a social environment to be critical to people's enjoyment, as it was when listening to music until the last century. In contrast, in many modern societies musical engagement often appears to be asocial-people will listen to music in the absence of social contact, and still enjoy the experience. While music being currently social is not critical to the hypothesis that music developed because of its social bonding effects, we would expect such a key feature to maintain importance over time, and its redundancy in modern societies appears paradoxical.

While this paradox could seem fatal for social cohesion accounts of the importance of music, the problem is surmountable if listening to music is always experienced as having potential social provenance. Below, I will argue that music has many properties that allow us to attribute it with agency, which is likely to mean it is experienced "socially," at least to the extent of believing another person has been involved in its creation or organization. Several potentially independent pathways might mediate this relationship and the relative contribution of each have yet to be empirically extricated from one another. When hearing music in the absence of performers we might associate musical sounds with the actions involved in producing those sounds, and therefore infer agency. If we have not had this direct exposure to musical movements (or if the sound is not associated with movement at all, as is the case for some electronic music) rhythm may be independently associated with movement (e.g. Chen, Penhume, \& Zatorre, 2008). While both of these mechanisms imply some engagement of motor regions of the brain, it is possible that rhythm and other hierarchically structured features of music tend to be attributed with human agency due to their organized nature, independently of any association with movement (e.g. Ma \& Xu, 2013). Finally, there is evidence that just being told that sound has been created by a person can lead to the activation of regions of the brain involved in social behavior during perception of that sound (Steinbeis \& Koelsch, 2009). These 
different pathways are outlined in Figure 1, and in combination they suggest that musical sounds are unlikely to ever be experienced asocially. This has important predictions and implications for the ways in which we enjoy recorded music.

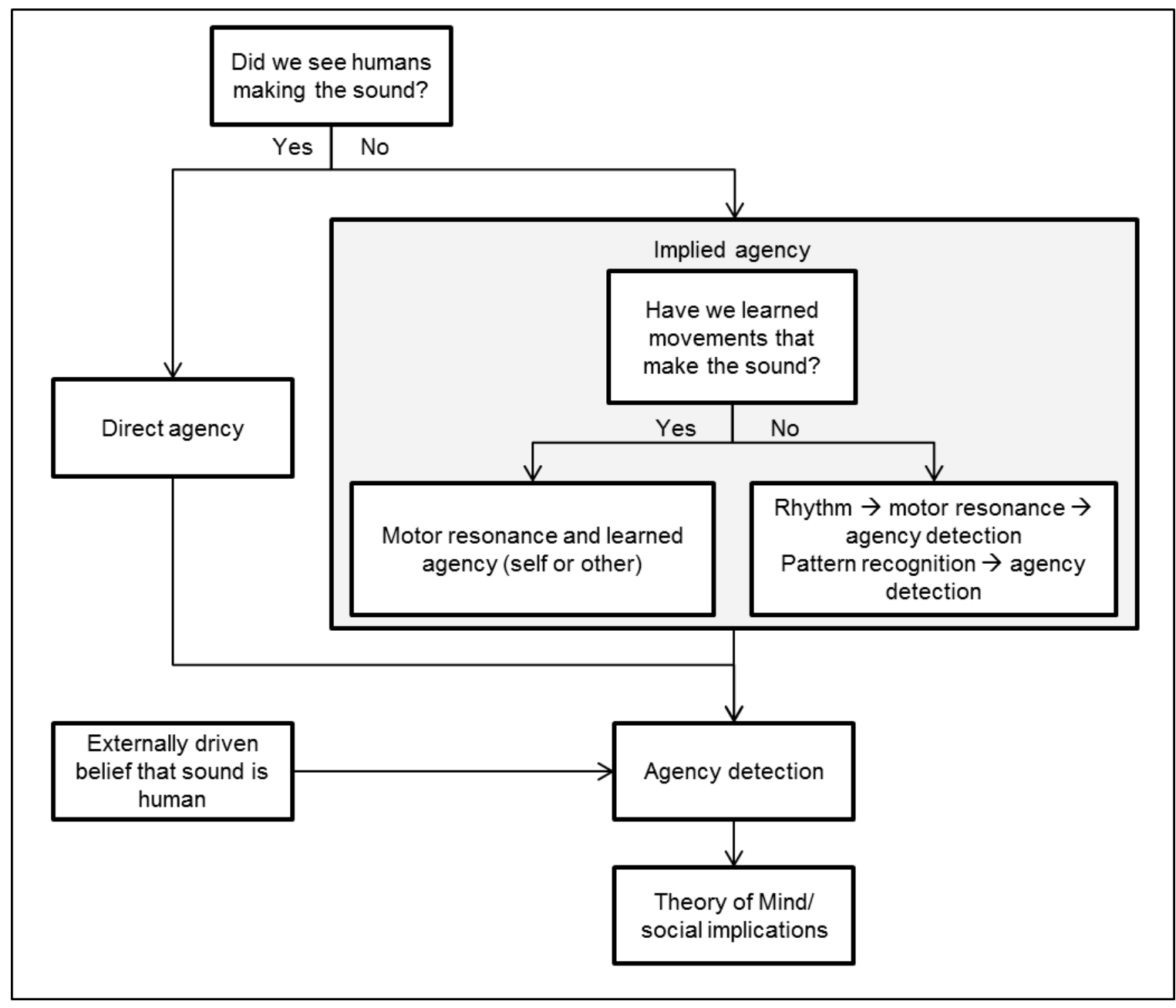

Figure 1. Potentially interacting pathways by which we might detect agency in musical sound.

\section{MOTOR RESONANCE AND DETECTING AGENCY WHEN WE HAVE LEARNED ASSOCIATIONS BETWEEN SOUND AND MOVEMENT}

Before discussing how music is associated with agency, I wish to introduce the argument that it has more direct resonance for listeners, via activation of motor regions of the brain. When experiencing this "motor resonance" for sound, we are also attributing that sound to an agent, whom we believe to have made the movements involved in creating it. In the past there has been much discussion of the social implications of activation of motor regions of the brain (e.g. Overy \& Molnar-Szakacs, 2009), but by following the causal pathway from different kinds of agent-driven sound it is clear that there are some gaps in our knowledge about whether motor resonance will occur for musical sound. Given these gaps, it is possible that alternative mechanisms for attributing musical sound with agency might be preferable, and these will be explored in the following sections of this paper.

It is now commonly accepted that there is a continuum between perception and action, so that the perception of sound can be a motor process for a listener. This was first introduced as a component of ideomotor theory (James, 1890), but there is now much empirical support to demonstrate that if people have 
clearly learnt associations between a sound and their own movement, regions of the brain involved in making that movement are active during the perception of that sound (Aziz-Zadeh, Maeda, Zaidel, Mazziotta, \& Iacoboni, 2002; Buccino et al., 2001; Buccino et al., 2004; Caetano, Jousmäki, \& Hari, 2007; Fadiga, Craighero, Buccino, \& Rizzolatti, 2002; Fadiga, Fogassi, Pavesi, \& Rizzolatti, 1995; Rizzolatti, 2005; Watkins, Strafella, \& Paus, 2003). While there is evidence that perception of sounds with welllearned associations with movement can engage motor regions of the brain, there are several additional processes involved for the same to be said of more abstract musical sounds. Motor empathy has been extensively discussed in the past, but it is important to recognize that there is currently limited evidence about the extent to which this occurs, and this limitation should be taken into account when discussing how music might influence social engagement.

The most direct evidence relating perceived and enacted movements shows that if we perceive a movement performed by another person it is likely to engage regions of the brain involved in making that movement ourselves. There is substantial evidence that this is the case for visually observed movement (Rizzolatti \& Craighero, 2004), and for movement that is heard (Aziz-Zadeh, Iacoboni, Zaidel, Wilson, \& Mazziotta, 2004; Aziz-Zadeh et al., 2002; Caetano et al., 2007). When viewing the actions of others, we are able to see that a human body part is involved and can think about making the same motion ourselves, which means that perception of these actions can be encoded using similar regions of the brain that are involved in making that movement, and agency is clearly detectable.

Sound, however, may be less obviously associated with particular movements or body parts. Speech has been studied more than other sounds in relation to connections between perception and action (e.g. Fadiga et al., 2002; Watkins et al., 2003), because it is clearly identifiable as sound with agency, has associations with movements that are known to listeners, and because motor resonance might have direct benefits for speech perception (the "motor theory" of speech perception, e.g. Galantucci, Fowler, \& Turvey, 2006). However, other sounds created by humans may have less clear associations with movement, and may be perceived quite differently by different listeners. A variety of commonly recognized hand action sounds have demonstrated motor resonant effects, such as fingers typing on a typewriter, hands clapping, and paper being ripped, (Aziz-Zadeh et al., 2004; Engel, Frum, Puce, Walker, \& Lewis, 2009; Lewis, Brefczynski, Phinney, Janik, \& DeYoe, 2005; Lewis, Phinney, Brefczynski-Lewis, \& DeYoe, 2006; Pizzamiglio et al., 2005), but there has not been extensive investigation of individual differences in motor resonance associated with familiarity with the performance of these actions. Learning has been shown to influence the relationship between perception of sound and action; greater training to associate a sound with movement makes motor resonance more likely, and indeed makes it possible in cases where there is no prior association known (Buccino et al., 2004; Lahav, Saltzman, \& Schlaug, 2007; Ticini, SchüzBosbach, Weiss, Casile, \& Waszak, 2012), particularly with regard to music. This evidence demonstrates that learning a relationship through making movements ourselves may play a role in the development of association between sound, movement, and agency.

It is important to distinguish between sounds associated with our own movement, and those associated with the movement of other people. Hearing sound that we associate with our own commonly performed movements may cause immediate and direct motor resonance, with sound being processed using motor regions of the brain, and a more general assumption that this sound is likely to be created by a human agent. However, hearing a sound that relates to movements that we have seen others make is less direct. For example, despite having never played a violin, people who have observed violin performances throughout their life may associate violin sounds with particular movements, meaning that regions of their brain involved in making those movements are engaged when listening to a violin being played in the absence of visual cues and agency. As perception of the movements of other people can be a motor process (Buccino et al., 2001), it is likely that associations between movements and sounds can be learnt through observation without active engagement. It has recently been shown that even short periods of learning to associate abstract sounds (i.e. computer-generated sounds with no inherent causal relationship with human movement) with the finger movement of another person can lead to subsequent motor resonance for those sounds (Launay, Dean, \& Bailes, under review). This demonstrates that it is not necessary to repeatedly pair our own movement with sound in order to learn associations, but that observation of the movements of another person can have a similar effect.

Although learning direct associations between sound and movement can occur when observing others, it is less clear that this is the case when people are not able to directly mirror the movements whilst the two are being paired. Evidence from studying people with apraxias suggests that losing the ability to move certain parts of the body impairs motor resonance when observing others moving that body part 
(Pazzaglia, Pizzamiglio, Pes, \& Aglioti, 2008), and a case study has shown that following stroke, predictions of the movements of another person can be impaired in a similar way to one's own performance (Eskenazi, Grosjean, Humphreys, \& Knoblich, 2009). So, while we would not expect active practicing of a movement to be vital in associating it with sound, patient studies suggest that the ability to make that movement is necessary in order to learn associations between sound and movement.

In all of the above cases, clear associations between movements and sound are learnt, which means that there is also a process of learning associations with agency. However, the majority of music listeners do not have explicitly learned associations between sound and the movements involved in making that sound. In these cases there should be some other mechanism for identifying agency.

\section{MOTOR RESONANCE AND DETECTING AGENCY WITHOUT LEARNING ASSOCIATIONS WITH MOVEMENT}

People engage with disembodied sound in many contexts in everyday life, and can often detect when these are created by a person and when they are not (e.g. when using a phone we are able to detect the difference between talking to a responsive person, hearing pre-recorded speech, hearing automated sounds, and even hearing non-human sounds that are agent-driven). This demonstrates that we do not necessarily have to learn specific relationships between movement and sound in order to perform agency detection. Importantly, when asked to describe a non-musical sound without being given other instruction the source of sound is prioritized rather than acoustic features such as loudness or pitch (Dibben, 2001; Gaver, 1993). While the source of non-musical sound appears to be the most relevant property to listeners, there is also a tendency to describe actions that might cause the sound more than the material that is being acted upon (e.g. the sound of paper being torn is more likely to be described as "tearing" than described as "paper"). This evidence suggests that we are in some way primed to identify implied agency (Ten Hoopen, 1994) even when it is not clearly detectable.

If we have not directly observed pairings between sound and movement, we might experience motor resonance through implied agency simply because we know that sound has been created by another person. For example, we may know how a violin works and have had the actions involved in its performance described to us without ever having observed these movements occurring during performance. While it is possible that this would cause motor resonance, it seems unlikely, and whether this degree of abstraction occurs is an outstanding empirical question. Even if evidence demonstrated that motor resonance can occur for sounds that have not been paired with movements it would not explain how people identify agency in musical sounds that are further removed from movement than this. With modern electronic music it is likely that listeners have no clear model about the movements that are being performed in order to create a sound, and that agency is not inferred via movement associations. This suggests that the agency paradox should be solved in some other way when people have not had the opportunity to directly pair sound with action and agency. One proposed mechanism is that we detect movement in the sound itself, rather than by reference to the actual movements known to be creating the sound.

A number of studies have attempted to address whether people do make reliable associations between features of music and potentially causal movement parameters (Eitan \& Granot, 2006; Eitan \& Rothschild, 2011; Friberg \& Sundberg, 1999; Merer, Ystad, Kronland-Martinet, \& Aramaki, 2008). Results suggest that individuals demonstrate large variability in the way that they map music to movements so this is likely to be influenced by individual experience, but that people are able to make associations fairly easily, suggesting the task is intuitive. Some relationships, such as that between tempo and movement speed, do appear to be reliable and evidence for this is further provided by neuroimaging studies, which demonstrate that motor regions of the brain are involved in processing rhythmic events (Chen, Penhune, \& Zatorre, 2008). However, perception of movement in rhythm may in itself be a developmentally learned process, independent of the identification of agency and movement related to a performer. For this reason, research on music and movement does not yet provide evidence that rhythmic sounds are inherently associated with movement.

Without directly learning to associate movement (either of our own, or of another person) with sound it might still be possible to have some motor resonance for that sound. However, this has not yet been convincingly shown, and further evidence should be collected to determine whether the knowledge that sound has been created by another person is sufficient to lead to motor resonance for that sound without having observed direct pairings between the two. While perception of rhythm associated with 
movement might also explain how motor resonance can occur during perception of musical sounds, there are more parsimonious explanations that do not invoke motor resonance at all, and these will now be outlined.

\section{DIRECT LINKS FROM MUSIC TO AGENCY DETECTION AND SOCIALITY}

Evidence reviewed so far has looked at how motor resonance can lead to agency detection in musical sounds. However, there might also be more direct ways that agency detection can occur, without motor resonance, one of which involves pattern detection. There is some evidence which demonstrates that for children, observation of objects arranged in regular patterns leads to a belief that these objects were organized by a human (Ma \& Xu, 2013). Given that many features of music involve hierarchical organization, it is likely that there will be a tendency for listeners to perceive agency in music, particularly if it is rhythmic, which is a relatively local form of hierarchical organization and can be easily identified. This is not to say that all rhythmic sounds will be detected as agent-driven (water dripping off a leaf might be correctly interpreted as a regular sound that emerges without purposeful agency), or that sounds that are non-rhythmic cannot be attributed with agency (e.g. free jazz), but that the regular patterns often involved in music may help to encourage listeners to perceive agency. While sound with repetition and organization are likely to be imbued with agency, it is subjective judgment of agency that is relevant to any listener, and this may be the consequence of lifetime experience and learning.

Finally, it is possible that agency detection occurs simply because we have an existing belief that an agent created or organized musical sound. A recent study (Steinbeis \& Koelsch, 2009) demonstrated that, compared with hearing a piece of music that is thought to have been composed by a computer, music that is attributed to a person is more likely to engage neural networks associated with theory of mind (the interpretation of the thoughts of other people, e.g. Tomasello, Carpenter, Call, Behne, \& Moll, 2005). In this experiment, by variously claiming that the same piece of music was created by a human agent or by a computer, the authors demonstrated that the attribution of agency to sound affected how it was perceived, without changing any acoustic properties of the sound. This experiment demonstrates a direct link from the attribution of agency to sound to the neural mechanisms that underlie social skills. Although relating movements to sound, and identifying rhythm in sound might both encourage people to identify agency, it is also possible for a direct link as a consequence of being told that sound is agent-driven.

It should be noted, however, that there is circularity in the definition of sounds with agency as given here: sounds attributed with agency are those which an individual attributes to an agent. This circularity makes the definition entirely subjective; sound that one listener perceives as random noise could be perceived by another listener as a carefully organized, meaningful piece of music. Attribution of agency influences perception, and the subjective nature of this attribution makes almost any sound potentially sound "with agency" if perceived in the right context. This means that while anyone observing a musical performance will be able to identify agency, recorded music allows some ambiguity in agency detection.

\section{THE RELATIONSHIP BETWEEN DETECTING AGENCY AND SOCIAL BEHAVIOR}

To review, music that is heard in the absence of performers is likely to be attributed with agency for several potential reasons, which are to some extent separable but are also likely to have some reciprocal relationships:

1. Learned associations may exist between the sounds involved and human movement (and therefore agency);

2. Rhythmic sounds may be perceived as related to movement, from which agency is inferred;

3. Hierarchically organized sounds may be directly associated with agency;

4. Being told that sound is organized by a person may lead to the activation of neural networks involved in social cognition.

Although I have repeatedly suggested that engaging with sound associated with agency might be a social experience, I have not yet explained what the consequences of this might be, including the influence on social behavior, or more emotional states such as empathy. While there has been speculation for many years about a relationship between motor resonance and other forms of empathy, there is little empirical 
evidence to suggest a direct relationship. In particular, an important distinction arises between cognitive empathy and emotional empathy, and evidence suggests that while motor resonance has a relationship with cognitive empathy (which may occur via theory of mind as outlined above), it is not necessarily associated with emotional empathy (Chartrand \& Bargh, 1999). This has been discussed in detail elsewhere (e.g. Baird, Scheffer, \& Wilson, 2011; Gonzalez-Liencres, Shamay-Tsoory, \& Brüne, 2013), and is not the point of major interest here. Instead, as the limits of our understanding of motor resonance have already been outlined, it is important to note that there is no clearly understood pathway from most musical engagement and empathy via motor resonance. The relationship that exists between attributing sound with agency and theory of mind, as outlined above, may account for connections that have been shown between empathy and musical sound. As such, we should be wary of overestimating the role of motor resonance in other forms of social cognition, and further empirical evidence should be collected to more explicitly explore this relationship.

If sounds with agency do create a sense of social engagement then we would expect them to be able to influence social behavior that occurs after the perception of these sounds. Specifically, there is already much support for the theory that synchronizing movements with the movements of another person can lead to increased affiliative behavior towards that person (Hove \& Risen, 2009; Valdesolo, Ouyang, \& DeSteno, 2010; Wiltermuth \& Heath, 2009). Recent work has shown that the same relationship between synchronization with the movements of another person can exist in the absence of visual contact with that partner (Launay, Dean, \& Bailes, 2013), but that this only occurs when sounds are attributed with human agency (Launay, Dean, \& Bailes, 2014). Importantly, even if it is not entirely clear how the attribution of agency to sound can affect high level social cognition, there can be consequences for ongoing social processes.

\section{IMPLICATIONS FOR MUSIC}

If perceiving sound with agency engages regions of the brain involved in interpretation of intentions, it becomes possible to identify meaning associated with that sound. It has been suggested that understanding meaning and agency is a prerequisite for appreciation of aesthetic arts, because an artistic work that involves a sense of agency (i.e. that has been purposefully organized by a thinking human agent), and a sense of movement can have some resonance for the person engaging with that work (Cinzia \& Vittorio, 2009; Freedberg \& Gallese, 2007; Godøy, 2010; Godøy, 2003; Leman, 2007; Molnar-Szakacs \& Overy, 2006). Appreciation of music is therefore likely to be affected by identifying that a human has organized or arranged the sounds that are heard, and this illustrates the importance of implied agency in sound, rather than direct interpretation of sounds as those that have been produced by a person.

Given that most adults have the capacity to use theory of mind, we would expect that hearing sound associated with other people engages this process. The study by Steinbeis and Koelsch (2009) is evidence that this is true: participants' belief that a piece of music was created by a person instead of a computer led to the engagement of neural networks involved in theory of mind (suggesting participants attempted to interpret the way that a composer had organized the musical sounds). In this example the sounds only had implied agency, so these types of sound can be sufficiently associated with agency to make engagement with them a "social" process, i.e. a process in which there is some attempt to interpret the intentions of another person. Music that people appreciate is always thought to be composed by another person. This might not seem to be the case with a piece of music that features randomly generated computer sounds, but a listener who identifies that as music is aware of the agent who engineered the random sound generation. This means it is likely that all music engages regions of the brain involved in theory of mind, and potentially regions of the brain involved in movement (although the limitations of this must be noted as listed in the section above). It is, therefore, almost inevitable that listening to music is a social experience.

Acousmatic sound was introduced by Pythagoras, and involved lecturing his students from behind a curtain so that they could concentrate on the content of his lectures rather than his physical presence. In the twentieth century acousmatics have been revived as a musical movement, in which everyday sounds (e.g. footsteps) are decontextualized and emphasis is placed on their acoustic properties rather than the source of sound. Within this music, and other forms of electronic music that remove visible agents from sound production, there is much recognition of the role that recognizing agency and movement in sound can play in the listeners' experience (e.g. Andean, 2012; Camilleri \& Smalley, 1998; Dean \& Bailes, 2007). Empirical evidence has shown that in electroacoustic music the presence of animate sounds can have a 
significant effect on the way that music is perceived (Dean \& Bailes, 2010). Given that identifiable agency could be entirely removed from music of this kind, it is important to note that researchers and musicians have repeatedly returned to the potential importance of agency detection.

Returning to the paradox that music is frequently listened to in the absence of a social environment we now have reasons to believe that this is not an entirely solitary process: if sounds are attributed with agency and potentially a sense of movement, then the experience of listening to music on headphones is inherently social. An interesting hypothesis arising from the argument that agency detection is important in musical engagement is that the spread of recorded music in the twentieth century should be paralleled by an increase in perceivable agency in the sound, especially for listeners who are not familiar with the instruments on which music is performed. This makes the prediction that since recording started, vocal music (which has inherent human agency) should have become relatively more popular than purely instrumental music, which should be harder for non-experts to attribute with human agency. With recorded instrumental music direct visual access to the movements of performers no longer occurs, and vocal music has the advantage that it can lead to direct resonance for the sounds being produced (Watkins et al., 2003), which would not be the case for other instruments if associations have not been learned with human agency. Further to this, we might also expect that recorded music enjoyed by non-musicians should have particularly strong rhythms and repetition, to further exaggerate a strong sense of agency. The transition from live to recorded music consumption has occurred in tandem with the commodification of music, which requires manufacturers to actively identify the features that make their music most marketable, and apply these principles in production, which is likely to lead to the exaggeration of any features that improve accessibility of music. Perhaps importantly, the transition to recorded music has been incremental, likely starting with notated pieces of music being exchanged, moving on to the use of records and tapes, and only recently moving to the trend for listening to iPods - it may be this slow transition that has allowed people to gradually adjust to what appears to be an asocial behavior. The discussion over the historical progression of listening to sound alone is speculative, but does demonstrate how facts could be used to test the current framework.

The argument made here suggests that when we listen to sounds alone we might be receiving a proto-social experience, and part of the pleasure gained from listening to music might derive from this experience, even if we may never meet the person to whom we are relating. Qualitative research investigating the reasons that people listen to music by themselves supports this idea. For example, when listening to music alone, people report that this creates the subjective experience of another human presence around them (North, Hargreaves, \& Hargreaves, 2004). When explaining the use of personal music devices in public spaces, people give reports such as "music makes me feel like I have company in my mood," (Bull, 2005, p. 352). This kind of response has been interpreted as the use of personal music devices to experience a social, but controlled environment, whilst involved in the more chaotic world of other people (Bull, 2005; Larsen, Lawson, \& Todd, 2009). These ideas suggest that listening to music might be a way of creating a miniature, controlled, social environment, and this is in accordance with the current findings which demonstrate that engaging with sounds attributed to other people can be a form of social engagement. Further investigations of the qualitative experience that people have of interacting with sound on their own could continue to explore the ramifications that this experience might have for construction of one's own social environment.

\section{CONCLUSIONS}

Here, I have discussed the problem that musical engagement is generally thought to be a form of social engagement, despite aspects of recent popular culture suggesting that this is not the case. While a surfacelevel understanding of musical listening when it occurs alone might suggest it is asocial, it is possible that through identification of human agency, sometimes in combination with motor resonance, engagement with any musical sound can be experienced in a social way. Qualitative, behavioral, and physiological data all provide empirical support for this theory. However, there are still several causal relationships on the pathway between musical sound and social engagement that are poorly investigated - in particular the relationship between motor resonance, rhythm processing, and empathic processes, and how these interact to influence higher-level social cognition. 


\section{ACKNOWLEDGEMENTS}

I would like to thank my Ph.D. supervisors Roger T. Dean and Freya Bailes, and members of the Music Sound and Action Group at MARCS Institute, University of Western Sydney for discussion of many of the matters discussed in this paper. I would also like to thank Eiluned Pearce and James Carney at the University of Oxford for their comments on draft versions of this paper, and Erin Gee for her advice. This work was partly funded by an Australian Endeavour International Postgraduate Research Scholarship, and partly by European Research Council Grant Number 295663.

\section{REFERENCES}

Andean, J. (2012). An embodied approach to acousmatic music. Paper presented at the The 16th Annual Symposium for Music Scholars in Jyväskylä, Finland.

Aziz-Zadeh, L., Iacoboni, M., Zaidel, E., Wilson, S., \& Mazziotta, J. (2004). Left hemisphere motor facilitation in response to manual action sounds. European Journal of Neuroscience, 19(9), 2609-2612.

Aziz-Zadeh, L., Maeda, F., Zaidel, E., Mazziotta, J., \& Iacoboni, M. (2002). Lateralization in motor facilitation during action observation: A TMS study. Experimental Brain Research, 144(1), 127-131.

Baird, A. D., Scheffer, I. E., \& Wilson, S. J. (2011). Mirror neuron system involvement in empathy: A critical look at the evidence. Social Neuroscience, 6(4), 327-335.

Bangert, M., Peschel, T., Schlaug, G., Rotte, M., Drescher, D., Hinrichs, H., Heinze, H. J., \& Altenmüller, E. (2006). Shared networks for auditory and motor processing in professional pianists: Evidence from fMRI conjunction. Neuroimage, 30(3), 917-926.

Blacking, J. (1973). How musical is man? Seattle: University of Washington Press.

Buccino, G., Binkofski, F., Fink, G. R., Fadiga, L., Fogassi, L., Gallese, V., Seitz, R. J., Zilles, K., Rizzolatti, G., \& Freund, H. J. (2001). Action observation activates premotor and parietal areas in a somatotopic manner: An fMRI study. European Journal of Neuroscience, 13(2), 400-404.

Buccino, G., Vogt, S., Ritzl, A., Fink, G. R., Zilles, K., Freund, H. J., \& Rizzolatti, G. (2004). Neural circuits underlying imitation learning of hand actions: An event-related fMRI study. Neuron, 42(2), 323334.

Bull, M. (2005). No dead air! The iPod and the culture of mobile listening. Leisure Studies, 24(4), 343-355.

Caetano, G., Jousmäki, V., \& Hari, R. (2007). Actor's and observer's primary motor cortices stabilize similarly after seen or heard motor actions. Proceedings of the National Academy of Sciences, 104(21), 9058-9062.

Camilleri, L., \& Smalley, D. (1998). The analysis of electroacoustic music: Introduction. Journal of New Music Research, 27(1-2), 3-12.

Chartrand, T. L., \& Bargh, J. A. (1999). The Chameleon effect: The perception-behavior link and social interaction. Journal of Personality and Social Psychology, 76(6), 893-910.

Chen, J. L., Penhune, V. B., \& Zatorre, R. J. (2008). Listening to musical rhythms recruits motor regions of the brain. Cerebral Cortex, 18(12), 2844-2854.

Cinzia, D.D., \& Vittorio, G. (2009). Neuroaesthetics: A review. Current Opinion in Neurobiology, 19(6), 682-687. 
Cross, I. \& Morley, I.(2009). The evolution of music: Theories, definitions and the nature of the evidence. In S. Malloch \& C. Trevarthen (Eds.), Communicative musicality: Exploring the basis of human companionship (pp. 61-81). New York: Oxford University Press.

Dean, R. T., \& Bailes, F. (2007). 'Human understanding' in imagining and organising sound: Some implications of John Locke's essay for ecological, cognitive and embodied approaches to composition. Organised Sound, 12(1), 89-95.

Dean, R. T., \& Bailes, F. (2010). Time series analysis as a method to examine acoustical influences on realtime perception of music. Empirical Musicology Review, 5(4), 152-175.

Dibben, N. (2001). What do we hear, when we hear music?: Music perception and musical material. Musicae Scientiae, 5(2), 161-194.

Eitan, Z., \& Granot, R. Y. (2006). How music moves. Music Perception, 23(3), 221-248.

Eitan, Z., \& Rothschild, I. (2011). How music touches: Musical parameters and listeners' audiotactile metaphorical mappings. Psychology of Music, 39(4), 440-467.

Engel, L. R., Frum, C., Puce, A., Walker, N. A., \& Lewis, J. W. (2009). Different categories of living and non-living sound-sources activate distinct cortical networks. Neuroimage, 47(4), 1778-1791.

Eskenazi, T., Grosjean, M., Humphreys, G. W., \& Knoblich, G. (2009). The role of motor simulation in action perception: A neuropsychological case study. Psychological Research, 73(4), 477-485.

Fadiga, L., Craighero, L., Buccino, G., \& Rizzolatti, G. (2002). Speech listening specifically modulates the excitability of tongue muscles: A TMS study. European Journal of Neuroscience, 15(2), 399-402.

Fadiga, L., Fogassi, L., Pavesi, G., \& Rizzolatti, G. (1995). Motor facilitation during action observation: A magnetic stimulation study. Journal of Neurophysiology, 73(6), 2608-2611.

Freedberg, D., \& Gallese, V. (2007). Motion, emotion and empathy in esthetic experience. Trends in Cognitive Sciences, 11(5), 197-203.

Friberg, A., \& Sundberg, J. (1999). Does music performance allude to locomotion? A model of final ritardandi derived from measurements of stopping runners. The Journal of the Acoustical Society of America, 105(3), 1469-1484.

Galantucci, B., Fowler, C. A., \& Turvey, M. T. (2006). The motor theory of speech perception reviewed. Psychonomic Bulletin \& Review, 13(3), 361-377.

Gaver, W. W. (1993). What in the world do we hear? An ecological approach to auditory event perception. Ecological Psychology, 5(1), 1-29.

Godøy, R. I. (2010). Images of sonic objects. Organised Sound, 15(1), 54-62.

Godøy, R. I. (2003). Motor-Mimetic music cognition. Leonardo, 36(4), 317-319.

Gonzalez-Liencres, C., Shamay-Tsoory, S. G., \& Brüne, M. (2013). Towards a neuroscience of empathy: Ontogeny, phylogeny, brain mechanisms, context and psychopathology. Neuroscience \& Biobehavioral Reviews, 37(8), 1537-1548.

Hagen, E. H., \& Bryant, G. A. (2003). Music and dance as a coalition signaling system. Human Nature: An Interdisciplinary Biosocial Perspective, 14(1), 21-51. 
Haueisen, J., \& Knösche, T. R. (2001). Involuntary motor activity in pianists evoked by music perception. Journal of Cognitive Neuroscience, 13(6), 786-792.

Hove, M. J., \& Risen, J. L. (2009). It's all in the timing: Interpersonal synchrony increases affiliation. Social Cognition, 27(6), 949-960.

Huron, D. (2001). Is music an evolutionary adaptation? Annals of the New York Academy of Sciences, 930, 43-61.

James, W. (1890). The principles of psychology (Vol. 2). New York: Dover Publications.

Lahav, A., Saltzman, E., \& Schlaug, G. (2007). Action representation of sound: Audiomotor recognition network while listening to newly acquired actions. Journal of Neuroscience, 27(2), 308-314.

Larsen, G., Lawson, R., \& Todd, S. (2009). The consumption of music as self-representation in social interaction. Australasian Marketing Journal, 17(1), 16-26.

Launay, J., Dean, R. T., \& Bailes, F. (2013). Synchronization can influence trust following virtual interaction. Experimental Psychology, 60(1), 53-63.

Launay, J., Dean, R. T., \& Bailes, F. (2014). Synchronising movement with the sounds of a virtual partner enhances partner likeability. Cognitive Processing, 5(4), 491-501.

Launay, J., Dean, R. T., \& Bailes, F. (under review). Rapid learning of associations between sound and action through observed movement: A TMS study.

Leman, M. (2007). Embodied music cognition and mediation technology. Cambridge, MA: MIT Press.

Lewis, J. W., Brefczynski, J. A., Phinney, R. E., Janik, J. J., \& DeYoe, E. A. (2005). Distinct cortical pathways for processing tool versus animal sounds. Journal of Neuroscience, 25(21), 5148-5158.

Lewis, J. W., Phinney, R. E., Brefczynski-Lewis, J. A., \& DeYoe, E. A. (2006). Lefties get it 'right' when hearing tool sounds. Journal of Cognitive Neuroscience, 18(8), 1314-1330.

Ma, L., \& Xu, F. (2013). Preverbal infants infer intentional agents from the perception of regularity. Developmental Psychology, 49(7), 1330-1337.

Merer, A., Ystad, S., Kronland-Martinet, R., \& Aramaki, M. (2008). Semiotics of sounds evoking motions: Categorization and acoustic features. Computer Music Modeling and Retrieval Conference Proceedings, 139-158.

Molnar-Szakacs, I., \& Overy, K. (2006). Music and mirror neurons: From motion to 'e'motion. Social Cognitive and Affective Neuroscience, 1(3), 235-241.

North, A. C., Hargreaves, D. J., \& Hargreaves, J. J. (2004). Uses of music in everyday life. Music Perception, 22(1), 41-77.

Overy, K., \& Molnar-Szakacs, I. (2009). Being together in time: Musical experience and the mirror neuron system. Music Perception, 26(5), 489-504.

Pazzaglia, M., Pizzamiglio, L., Pes, E., \& Aglioti, S. M. (2008). The sound of actions in apraxia. Current Biology, 18(22), 1766-1772

Pinker, S. (1997). How the mind works. New York: Norton. 
Pizzamiglio, L., Aprile, T., Spitoni, G., Pitzalis, S., Bates, E., D'Amico, S., \& Di Russo, F. (2005). Separate neural systems for processing action-or non-action-related sounds. Neuroimage, 24(3), 852-861.

Rizzolatti, G. (2005). The mirror neuron system and its function in humans. Anatomy and Embryology, 210(5), 419-421.

Rizzolatti, G., \& Craighero, L. (2004). The mirror-neuron system. Annual Review of Neuroscience, 27, 169-192.

Steinbeis, N., \& Koelsch, S. (2009). Understanding the intentions behind man-made products elicits neural activity in areas dedicated to mental state attribution. Cerebral Cortex, 19(3), 619-623.

Ten Hoopen, C. (1994). Issues in timbre and perception. Contemporary Music Review, 10(2), 61-71.

Ticini, L. F., Schüz-Bosbach, S., Weiss, C., Casile, A., \& Waszak, F. (2012). When sounds become actions: Higher-order representation of newly learnt action sounds in the human motor system. Journal of Cognitive Neuroscience, 24(2), 464-474.

Tomasello, M., Carpenter, M., Call, J., Behne, T., \& Moll, H. (2005). Understanding and sharing intentions: The origins of cultural cognition. Behavioral and Brain Sciences, 28(5), 675-735.

Valdesolo, P., Ouyang, J., \& DeSteno, D. (2010). The rhythm of joint action: Synchrony promotes cooperative ability. Journal of Experimental Social Psychology, 46(4), 693-695.

Watkins, K. E., Strafella, A. P., \& Paus, T. (2003). Seeing and hearing speech excites the motor system involved in speech production. Neuropsychologia, 41(8), 989-994.

Wiltermuth, S. S., \& Heath, C. (2009). Synchrony and cooperation. Psychological Science, 20(1), 1-5. 